unhealthy temperature, and no cow that has a persistent temperature of $102^{\circ} \mathrm{F}$. can give a wholesome milk.

The conditions and methods here set forth are those that almost universally prevailed on Long Island when this food was used; and the milk, which I have analyzed, and which was referred to in previous numbers of this journal, was produced under these conditions.

The chemical features of the milk which are most marked, are, the strongly acid re-action, deficiency of fat and sugar, and great excess of caseine or curd. So marked were these features, that I was able to identify swill-milk produced under these conditions.

That such milk is a dangerous food for young children, I have had abundant clinical evidence. The tough, hard curd produced in the stomach by this milk is entirely too much for the digestive powers of even healthy children, and passes undigested, irritating the intestinal mucous membrane throughout its entire length, giving rise to intestinal catarrh, inflammatory diarrhœea, or cholera-infantum. Occasionally the curd formed in the stomach is too large and firm to pass the pyloris, when the child passes into rapid collapse and death, unable to rid the stomach of the mass either by vomiting or purging. Remedies, under such circumstances, are of no avail. I have seen the same effects, in a somewhat less degree, produced in adults who were not disturbed by a pure, wholesome milk.

I think we may accept it as demonstrated, Ist, that fed as it has always been in this vicinity, distillery-swill is an unfit food for milch-cows, as it deteriorates the health of the cows, and produces unwholesome milk; 2 d, from the difficulty of perfectly controlling the manner of feeding, it is not warrantable for any sanitary authority to recommend it as a food for milch-cows ; 3 d, it has not yet been proven that it can be successfully fed in conjunction with other wholesome food; 4 th, the laws now in force in this and other States, forbidding the sale of swill-milk, are justifiable, and should be enforced.

Brooklyn, July 23.

E. H. BARTLEy, M.D.

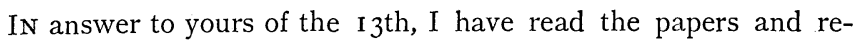
ports on distillery-swill milk published in Science, and, in my judgment, you have furnished reasonable evidence of the unwholesomeness of such milk as a general fact. I mean where distillery-swill constitutes the chief food of the animals.

From the very nature of the case, complete proof and absolute demonstration by direct, full, and conclusive experiments cannot be had : so we must rely on such evidence as is available, the same as in so many other sanitary questions where the deductions have to be derived from a great mass of cumulative evidence, each single fact in which is inconclusive. I have therefore only to suggest that you continue the recording of facts as the only available way either of arriving at just conclusions or of convincing the public of the truthfulness of the conclusions.

I know of no conclusion in sanitation so well established that men may not be found to deny it; and, so long as distillery-swill milk does not kill or sicken all who may use any of it, there will probably be persons who deny that it is harmful to any.

The correspondent in Science of July 22 (p. 46) fails to find "positive evidence" of " any ill effects of swill upon cows fed with it." On the other hand, he asserts, as if on "positive evidence," that " the evils attributable to it are largely, if not entirely, to be ascribed to the unsanitary surroundings of the animals." I hardly know how comprehensive and sweeping he intends this to apply. It would be unfair to charge him with asserting that the almost universal disease in distillery stables, the emaciation, the lax bowels, the loss of teeth, the short lives in such stables as distinguished from those where hay and grain are the chief food, and the "unsanitary surroundings of the animals" in these stables, as a rule, should be merely curious coincidences, and not due to the feeding of the swill itself. His language implies all this, but surely I can hardly believe that to be his meaning.

Some supplementary statements, however, are equally positive and equally striking, - the proposition " that lactation in a dairy is not a normal process," and that he regards the conclusions (if not, indeed, the facts) given by certain chemists and physicians, regarding the nature and digestibility of the curd of swill-milk, as on the whole unworthy of confidence.

If you can convince a.few orphan-asylums and foundling-hospitals that it would be an innocent and harmless experiment to feed half of their children on distillery-swill milk, and the other on grass-andgrain milk, and continue this experiment for several years, on different races of children, in different localities, some of the swill-milk stables to be kept as clean as other stables may be, by some process not yet announced, and carefully record and collate all the results, the question would then be settled, in the usual acceptance of that term.

Until some such plan for " positive evidence" be secured, I suggest that you work at the method of cumulative evidence which has been so rich in conclusions and beneficent in its results in other departments of sanitary science.

New Haven, Conn., July 25.

\section{State Interference.}

Copies of Science containing two of the articles on State interference have been received; also your note asking opinions respecting them.

I am glad you undertook the investigation, and wish it might have called forth more elaborate replies. It is a subject which ought to be worked up carefully for all the States and for a period of years long enough to show the working of tendencies.

But, so far as the facts you have presented go, I see very little which will not be found upon the statute-books of England, which is generally known as the classic land of laissez faire. The protective system involves more serious interference with private concerns than almost any of the new laws. Our legislators, I admit, are ignorant, and moved largely by party or private interest; but that is the fault of our political system, and is connected with the essentially commercial character of the people. The social question is upon us: we must have laws regulating competition to a certain extent. The danger comes, not from the tendency toward such regulation, but from the character of the men to whom legislation is intrusted: hence the necessity of civil-service reform, of higher political education, and of a strengthening of the moral tone of the people.

Short Beach, Conn., July 23.

H. L. OSGOOD.

\section{Tornado Force.}

MR. E. B. GARRIATT has a communication on tornado power in your issue of July 22, in which he complains of the "disposition, on the part of writers on scientific subjects, ... to sacrifice common-sense reasoning and probable facts to profound but improbable theories," and then proceeds to explain tornado energy as due to electricity, and not to wind. To support this view, he makes the statement, first, that "moist air is one of the best known conductors of electricity;" and, second, that the "earth is the great reservoir for the electric fluid." It might be worth the while for Mr. Garriatt to assure himself of the truth of his fundamental principles before he applies them on so large a scale. There is not the slightest experimental evidence that moist air is a conductor at all, much less "one of the best;" and as for the earth being a reservoir of electricity, every thing that is known about electricity negatives the idea.

Again : it is implied that electrical energy is more destructive than other kinds, as if a definite quantity of it could do more work than an equal quantity of other energy. He also speaks of "the electric fluid." These quotations show that he has no practical acquaintance with what physicists call 'electricity ;' that he does not understand the laws of its generation, the conditions of its transferrence, nor its quantitative relation to other forms of energy; and therefore, to quote still further from his article, it is " unsatisfactory and worthless from a practical scientific standpoint."

College Hill, Mass., July 23 .

A. E. Dolbear.

\section{Answers.}

ro. Robin's NEST. - The ten-storied robin's nest mentioned in Science of July 22 is indeed a remarkable affair. It is rather unusual for robins to build a new nest on an old one, although it sometimes happens. I have seen a number of two-storied nests, and one three-storied one, but such nests are rare. J. A. AllEN. - New York, July 26. 